\title{
Perhitungan Tarif INA-CBG Terhadap Tarif Real Rumah Sakit Dengan Menggunakan Metode Activity Based Costing Pada Pasien PPOK
}

\author{
Handa Meru Erio Rakihara', Titiek Hidayati ${ }^{2}$
}

${ }^{1}$ Program Studi Manajemen Rumah Sakit, Universitas Muhammadiyah Yogakarta ${ }^{2}$ Departemen Kesehatan Masyarakat dan Keluarga, Fakultas Kedokteran dan Ilmu kesehatan, Universitas Muhammadiyah Yogakarta eriorakihara@gmail.com, ${ }^{2}$ hidayatifkumy@yahoo.co.id *Corresponding author

\begin{tabular}{l}
\hline Informasi artikel \\
Received: 11-04-2020 \\
Revised: 21-04-2020 \\
Accepted: $30-05-2020$
\end{tabular}

\section{Kata kunci:}

Activity Based Costing (ABC),

Penyakit Paru Obstruksi

Kronis,

Unit Cost \begin{abstract}
ABSTRAK Penyakit Paru Obstruktif Kronis (PPOK) adalah penyakit dengan karakteristik keterbatasan saluran napas yang tidak sepenuhnya reversible. Keterbatasan saluran napas tersebut biasanya progresif dan berhubungan dengan respons inflamasi dikarenakan bahan yang merugikan atau gas. The Burden Of Disease Study dibawah naungan WHO menyatakan bahwa PPOK menjadi penyebab kematian, yang sebelumnya menempati urutan ke-6 berubah menjadi urutan ke-3 pada tahun 2020. RS Paru Respira Yogyakarta menerima pasien umum maupun pasien asuransi, dan sudah mengadakan kerjasama dengan Badan Penyelengara Jaminan Sosial Kesehatan, sehingga penggantian pembayaran pasien-pasien BPJS disesuaikan dengan tarif Indonesia Case Base Groups sesuai dengan klasifikasi tipe dan regionalitas. Sehingga penelitian ini dilakukan bertujuan untuk menghitung unit cost dengan metode Activity Based Costing (ABC) perawatan pasien Penyakit Paru Obstruksi Kronis dan kemudian di bandingkan dengan real cost dan tarif INA CBG's.Jenis penelitian ini deskriptif kualitatif dengan rancangan studi kasus pada RS Respira Yogyakarta, kasus yang dipilih adalah pasien yang memiliki diagnosis ICD X : J-4-17-III (Penyakit Paru Obstruksi Kronis Berat).Hasil Perhitungan unit cost pasien Penyakit Paru Obstruksi Kronis dengan metode $\mathrm{ABC}$ adalah $\mathrm{Rp}$ 4.851.150,00 yang terdiri dari biaya langsung yaitu sebesar Rp 1.735.050,00 dan biaya overhead sebesar Rp 3.116.100,00. Berdasarkan perhitungan unit cost untuk pasien Penyakit Paru Obstruksi Kronis adalah sebesar Rp 4.851.150,00 terdapat selisih Rp 2.134.450,00 dengan real cost yang ada di RS Respira Yogyakarta dan selisih sebesar Rp 1.442.814,00 dengan tarif INA CBG's.
\end{abstract}

Keywords : Activity Based Costing (ABC),

Chronic Obstructive Pulmonary Disease, Unit Cost

\section{ABSTRACT}

Chronic Obstructive Pulmonary Disease (COPD) is a disease with limit airway characteristics that not completely reversible. Airway limitation usually progressive and correlates with inflammation response due to harmful material or gas. The Burden Of Disease Study under auspices of The World Health Organization stated that COPD is the cause of death, who previously ranked 6th and in 2020 it can become 3rd as the most common cause of death. Respira Lung Hospital Yogyakarta accepts general patient and patient with insurance, also they already cooperate with BPJS, with the result that replacement of BPJS patient's payments are adjusted to Indonesia Case Base Groups rates in accordance with type classification and regionality. This study has the goal to count unit cost using Activity Based Costing (ABC) method in Chronic Obstructive Pulmonary Disease patient's care and to compare it with real cost and INA-CBG's fare.This research is using descriptive qualitative with case study design in Respira Lung Hospital Yogyakarta, the chosen cases are patients that already diagnosed ICD X: J-417-III (Chronic Obstructive Pulmonary Disease). Result : The result of unit cost calculation on Chronic Obstructive Pulmonary Disease patient with ABC method is $\mathrm{Rp} 4.851 .150,00$ consist of direct cost $\mathrm{Rp} 1.735 .050,00$ and overhead cost $\mathrm{Rp}$ 3.116.100,00. According to unit cost calculation for Chronic Obstructive Pulmonary Disease patient it counts Rp 4.851.150,00 
and has difference Rp 2.134.450,00 with real cost in Respira Lung Hospital Yogyakarta and $\mathrm{Rp} 1.442 .814,00$ with INA CBG's fare.

\section{PENDAHULUAN}

Rumah Sakit adalah institusi pelayanan kesehatan bagi masyarakat dengan karateristik tersendiri yang dipengaruhi oleh perkembangan ilmu pengetahuan kesehatan, kemajuan teknologi, dan kehidupan sosial ekonomi masyarakat yang harus tetap mampu meningkatkan pelayanan yang lebih bermutu dan terjangkau oleh masyarakat agar terwujud derajat kesehatan yang setinggi-tingginya (Undang-Undang Nomor 44 Tahun 2009). Menurut Global Initiative for Chronic Obstructive Lung Disease (GOLD), Penyakit Paru Obstruktif Kronis (PPOK) adalah penyakit dengan karakteristik keterbatasan saluran napas yang tidak sepenuhnya reversible. Keterbatasan saluran napas tersebut biasanya progresif dan berhubungan dengan respons inflamasi dikarenakan bahan yang merugikan atau gas. The Burden Of Disease Study dibawah naungan WHO menyatakan bahwa PPOK menjadi penyebab kematian, yang sebelumnya menempati urutan ke-6 berubah menjadi urutan ke-3 pada tahun 2020 (WHO,2001)

RS Paru Respira Yogyakarta menerima pasien umum maupun pasien asuransi, dan sudah mengadakan kerjasama dengan BPJS, sehingga penggantian pembayaran pasien-pasien BPJS disesuaikan dengan tarif INA-CBG's sesuai dengan klasifikasi tipe dan regionalitas RS Paru Respira Yogyakarta. Berdasarkan Surat Keputusan Menteri Kesehatan Nomor 560 /MENKES /SK/ IV/ 2003 pasal 3 tentang pola tarif Rumah Sakit diperhitungkan atas dasar unit cost dari setiap jenis pelayanan dan kelas perawatan, yang perhitungannya memperhatikan kemampuan ekonomi masyarakat, standar biaya dan atau benchmarking dari rumah sakit yang tidak komersil (Keputusan Menteri Kesehatan Republik Indonesia Nomor 560, 2003). Keputusan menteri tersebut, setiap rumah sakit harus mulai sadar akan pentingnya perhitungan tarif yang relevan dan sesuai dengan fasilitas yang diberikan kepada pasien.

Sistem Activity Based Cost (ABC) merupakan sebuah sistem informasi akuntansi yang mengidentifikasikan bermacam-macam aktivitas yang dikerjakan dalam suatu organisasi dan mengumpulkan biaya dengan dasar sifat yang ada dari aktivitas yang digunakan untuk mengatasi kelemahan akuntansi biaya akuntansi tradisional. Sistem kerja Metode ABC banyak diterapkan pada perusahaan manufaktur, tetapi juga dapat diterapkan pada perusahaan jasa seperti rumah sakit (Indra Bastian, 2008). Menurut Indra Bastian (2008: 227) manajemen organisasi kesehatan membutuhkan informasi lengkap tentang aktivitas yang bisa diketahui melalui clinical pathway yang merupakan pedoman yang mencakup semua aktivitas pasien mulai saat masuk hingga keluar dari rumah sakit.

Tujuan dari penelitian ini adalah Untuk mengevaluasi perhitungan unit cost PPOK dengan metode Activity Based Costing (ABC) di Rumah Sakit Respira Yogyakarta, Untuk mengetahui selisih antara perhitungan unit cost PPOK dengan metode Activity Based Costing (ABC) dengan Real Cost yang ditetapkan RS dan tarif INA CBG's yang didapat oleh RS Respira Yogyakarta. Keaslian penelitian: Winny Ardhitiya Garini, 2016. Analisis Biaya Satuan pada Pasien Rawat Inap Diabetes Melitus Tipe 2 dengan Metode Activity Based Costing Di RS PKU Muhammadiyah Bantul. Bedanya adalah penelitian ini menghitung Unit Cost diagnosis PPOK dari pasien masuk ke Rumah Sakit sampai pasien keluar Rumah Sakit. Kemudian Unit Cost yang didapat di bandingkan dengan Real Cost dan tarif yang diganti oleh INA-CBG's untuk diagnosis PPOK pada RS Respira Yogyakarta.

\section{METODE PENELITIAN}

Penelitian ini mendeskripsikan mengenai unit cost yang berhubungan dengan layanan rawat inap pasien dengan diagnosis PPOK yang dihitung menggunakan metode $\mathrm{ABC}$ pada pasien BPJS di RS Respira Yogyakarta. Penelitian dilaksanakan untuk pengabilan data selama tahun 2017. Dalam penelitian ini, subjek penelitian adalah Kepala Bagian Keuangan, Dokter Spesialis Paru, kepala rawat inap, petugas administrasi seperti petugas pendaftaran, rekam medis, bagian mutu, bagian pemasaran dan kesekertariatan Rumah Sakit Respira Yogyakarta. Sementara itu untuk objek penelitian nya adalah semua aktivitas yang 
dilakukan untuk menghasilkan produk layanan jasa layanan diagnosis PPOK di RS Respira Yogyakarta. Variabel dari penelitian ini adalah unit cost pelayanan perawatan yang diagnosis PPOK dirawat inap di RS Respira Yogyakarta. Tahapan yang harus dilalui pada penelitian ini adalah planning, acting, observing, dan reflecting. Kegiatan tahapan ini dilakukan dengan sekali pengambilan dalam suatu waktu namun bertahap secara perizinan rumah sakit yang bersangkutan. Pada planning penelitian dilakukan dengan merancang latar belakang hingga jenis desain dan menentukan tempat serta waktu untuk pengambilan contoh perhitungan unit cost dari populasi tindakan layanan diagnosis PPOK di RS Respira Yogyakarta. Acting adalah dengan mengambil data observasional dari bagian keuangan atau administrasi dengan disertai permohonan perizinan pengambilan. Observing dilakukan dengan mengamati data serta men-sortir yang sesuai dengan pemasukan dan pengeluaran Rumah Sakit. Reflecting sendiri dilakukan dengan membandingkan tiap siklusnya tahapan kemudian dibandingkan dengan tarif real dari INA-CBG's yang dibayarkan ke Rumah Sakit apakah terdapat selisih untung ataukah RS mengalami kerugian.

\section{Hasil Penelitian dan Pembahasan}

Proses perhitungan biaya satuan (unit cost) pasien rawat inap Penyakit Paru Obstruksi Kronis dengan menggunakan metode $\mathrm{ABC}$ dengan langkah-langkah sebagai berikut. Biaya langsung atau direct cost adalah biaya langsung yang muncul ketika suatu diagnosis ditegakkan. Biaya langsung dibebankan secara langsung ke produk atau jasa. Biaya ini dibebankan sebagai cost produk atau jasa yang bersangkutan. Untuk tindakan biaya langsung yang muncul adalah Rp 1.735.050,00 Menentukan besarnya biaya direct resource overhead dan indirect resource overhead yang dikonsumsi masing-masing aktivitas dengan menggunakan proporsi waktu pada unit terkait yaitu Instalasi Gawat Darurat (IGD) dan Bangsal non infeksi.

1) Biaya indirect resource overhead Biaya pegawai adalah gaji, tunjangan karyawan (insentif dan tunjangan hadir), lembur pegawai, seragam, makan, dana kesehatan serta biaya pendidikan dan pelatihan.
Biaya seluruh indirect resource overhead RSKP Respira Yogyakarta sebesar Rp. 7.492.847.971,00 yang akan dibebankan kepada unit fungsional RSKP Respira Yogyakarta dengan menggunakan dasar proporsi pendapatan di masingmasing unit fungsional.

a) Instalasi Gawat Darurat (IGD)

Berdasarkan perhitungan biaya indirect resource overhead RSKP Respira Yogyakarta maka IGD mendapat pembebanan sebesar Rp 1.152.755.571,00 yang akan dibebankan pada seluruh pasien IGD pada tahun 2017 yaitu 2.782 pasien, sehingga untuk perpasien akan mendapatkan pembebanan indirect resource overhead sebesar Rp 414.362,00.

b) Bangsal non Infeksi

Biaya indirect resource overhead yang dibebankan akan di proporsikan menjadi pembebanan biaya indirect resource overhead per setiap hari rawat (LOS). Bangsal non infeksi selama tahun 2017 jumlah hari rawat sebanyak 2.355 hari rawat, sehingga untuk perpasien akan mendapatkan pembebanan indirect resource overhead sebesar $\mathrm{Rp} \quad 186.473$.

2) Biaya direct resource overhead Dapat dilihat pada masing-masing unit yang terkait :

a. Instalasi gawat darurat (IGD)

Unit IGD memiliki jumlah pegawai 15 orang dengan jumlah pasien 2.782 orang pada tahun 2017. Untuk biaya pegawai unit IGD pada tahun 2017 adalah sebesar Rp 419.369.373,00 sehingga untuk satu orang pegawai selama satu tahun mengeluarkan biaya sebesar Rp 27.957.958,00. Gedung IGD masih memiliki umur ekonomis sehingga untuk biaya depresiasi gedung IGD pertahun Rp 32.925.263,00. Sehingga satu pasien akan menanggung biaya direct resource overhead unit IGD sebesar Rp $364.110,00$

b. Bangsal non Infeksi

Unit bangsal non infeksi memiliki pegawai sejumlah 25 orang dengan jumlah hari rawat sebanyak 2.355 hari pada tahun 2017. Untuk biaya pegawai unit bangsal non infeksi selama tahun 2017 adalah sebesar Rp 698.948.955,00 sehingga untuk satu orang pegawai selama satu tahun mengeluarkan biaya sebesar Rp27.957.958,00. Gedung unit bangsal non infeksi masih memiliki umur ekonomis sehingga untuk biaya depresiasi gedung unit bangsal non infeksi pertahun $\mathrm{Rp}$ 254.205.004,00. sehingga satu pasien akan menanggung biaya direct resource 
overhead unit bangsal non infeksi sebesar Rp 521.899,00.

3) Total biaya overhead

Setelah melakukan perhitungan indirect resource overhead dan direct resource overhead maka dapat diketahui biaya total overhead

Tabel 1. Total Biaya Overhead Rumah Sakit

\begin{tabular}{|c|c|c|c|}
\hline \multirow{3}{*}{$\begin{array}{c}\text { Unit } \\
\text { Rumah } \\
\text { Sakit }\end{array}$} & \multicolumn{2}{|c|}{ Biaya Overhead } & \multirow{3}{*}{$\begin{array}{c}\text { Total } \\
\text { Biaya } \\
\text { Overhea } \\
\text { d }^{(\mathrm{c})}(\mathrm{Rp})\end{array}$} \\
\hline & Indirect & Direct & \\
\hline & $\begin{array}{l}\text { resource } \\
\text { (a) }(\mathrm{Rp})\end{array}$ & $\begin{array}{l}\text { resource } \\
\text { (b) }(\mathrm{Rp})\end{array}$ & \\
\hline IGD & 414.362 & 364.110 & 778.472 \\
\hline $\begin{array}{l}\text { Bangsal } \\
\text { non } \\
\text { infeksi }\end{array}$ & 186.473 & 521.899 & 708.372 \\
\hline
\end{tabular}

Ket : $\mathrm{c}=\mathrm{a}+\mathrm{b}, \mathrm{a}=$ indirect resource, $\mathrm{b}=$

direct resource, $\mathrm{c}=$ total biaya overhead

Tahap selanjutnya dari perhitungan biaya satuan dengan betode $\mathrm{ABC}$ menurut Baker (1998) adalah membebankan biaya overhead ke masing-masing aktivitas.

1) Instalasi gawat darurat (IGD)

Pembebanan biaya indirect resource overhead pada unit IGD secara total berdasarkan biaya yaitu waktu dan aktivitas sebesar Rp 414.362,00 sedangkan pembebanan biaya direct resource overhead pada unit IGD secara total berdasarkan pemicu biaya yaitu waktu dan aktivitas sebesar Rp 364.110,00.

2) Bangsal non infeksi

Pembebanan biaya indirect resource overhead pada bangsal non infeksi secara total berdasarkan pemicu biaya, adalah waktu dan aktivitas sebesar Rp 615.361,00 sedangkan pembebanan biaya direct resource overhead pada unit bangsal non infeksi secara total berdasarkan pemicu biaya, waktu dan aktivitas adalah $\mathrm{Rp}$ 1.722.267,00.

Menurut perhitungan di atas didapatkan unit cost pasien rawat inap Penyakit Paru Obstruksi Kronik dengan metode ABC sebesar Rp 4.851.150,00.

\section{a. Beban Biaya langsung dalam perhitungan unit cost pasien rawat inap Penyakit Paru Obstruksi Kronik}

Beban biaya langsung pada rawat inap pasien Penyakit Paru Obstruksi Kronik adalah sebesar $\mathrm{Rp} 1.735 .050,00$ atau sebesar $18,2 \%$ dari total beban biaya rawat inap pasien Penyakit Paru Obstruksi Kronik. Tingginya beban biaya langsung pada perawatan pasien dikarenakan biaya pemeriksaan barang habis pakai dan obat sebesar Rp 409.550,00 (23,6 \% total biaya langsung), laboratorium dan penunjang yaitu sebesar Rp 356.000,00 (20,5 \% dari total biaya langsung), biaya administrasi sebesar Rp 37.000,00 (2,1\% dari total biaya langsung) dan biaya jasa medis dokter dan ahli gizi sebesar Rp 342.500,00 ( 19,7\% dari total biaya langsung).

\section{b. Beban Biaya overhead dalam perhitungan unit cost rawat inap pasien Penyakit Paru Obstruksi Kronik}

Beban biaya overhead rawat inap pasien PPOK yaitu sebesar Rp. 3.116.100,00 atau sebesar 64,23\% dari total beban biaya perawatan pasien. Beban biaya tersebut terbagi dalam, biaya overhead di IGD yaitu sebesar Rp. 778.472,00 atau sebesar $16,04 \%$ dari biaya total, dan biaya overhead di Bangsal non infeksi sebesar Rp. 2.337.628,00 atau sebesar 48,18\% dari total biaya perawatan pasien PPOK.

Menurut peneliti rendahnya biaya indirect resource overhead disebabkan karena biaya total keseluruhan yang ada di Rumah Sakit dibebankan kepada seluruh unit fungsional yang ada di rumah sakit meliputi unit rawat inap sebesar $24,75 \%$, unit rawat jalan sebesar 11,88\%, instalasi bedah sentral sebesar 11,88\%, unit IGD sebesar 14,85\% dan unit penunjang sebesar 36,63\% , sedangkan untuk biaya direct resource overhead hanya dibebankan pada unit itu sendiri sehingga menyebabkan biaya direct resource overhead lebih besar dibandingkan biaya indirect resource overhead.

\section{c. Unit Cost Pasien Rawat Inap PPOK melalui perhitungan Activity Based Costing dan Real Cost di RSKP Respira Yogyakarta.}

Hasil perhitungan unit cost pasien rawat inap PPOK dengan menggunakan metode activity based costing adalah $\mathrm{Rp}$ 4.851.150,00 dan dari perhitungan real cost menggunakan kebijakan manajemen diperoleh Rp 2.716.700,00 sedangkan klaim dari BPJS untuk diagnosis J-4-17-III adalah sebesar $\mathrm{Rp}$ 3.408.336,00

Perhitungan unit cost pasien rawat inap PPOK dengan metode $A B C$ yaitu sebesar Rp 4.851.150,00 dengan biaya langsung yaitu sebesar $\mathrm{Rp}$ 1.735.050,00 dan biaya overhead sebesar Rp 3.116.100,00 sedangkan real cost RS Respira Yogyakarta sebesar $\mathrm{Rp}$ 2.716.700,00 sehingga didapatkan selisih sebesar Rp 2.134.450,00 yang berarti Real Cost yang ditetapkan oleh RS Respira Yogyakarta belum mampu 
untuk membiayai beban biaya langsung dan biaya overhead.

Selisih antara unit cost metode $\mathrm{ABC}$ dan tarif INA CBG disebabkan karena metode perhitungan yang tidak sama. Besarnya klaim tarif INA CBG yang diberikan oleh pemerintah didapatkan dari hasil perhitungan beberapa rumah sakit sesuai dengan tipe rumah sakit. Besarnya klaim dari BPJS tergantung dari diagnosis, regional wilayah Rumah sakit dan Tipe Rumah sakit. Menurut peneliti proses pengkodingan yang ada di rumah sakit juga mempengaruhi untuk klaim yang akan di berikan.

\section{KESIMPULAN}

1. Biaya satuan (unit cost) pasien rawat inap PPOK di RS Respira Yogyakarta menggunakan metode activity Based Costing adalah $\mathrm{Rp} 4.851 .150,00$

2. Terdapat perbedaan antara unit cost metode $\mathrm{ABC}$ dengan real cost yang diterapkan di RS Respira Yogyakarta yaitu sebesar Rp 2.134.450,00 dimana unit cost dengan metode $\mathrm{ABC}$ lebih tinggi dibandingkan real cost yang diterapkan di RS Respira Yogyakarta.

3. Terdapat perbedaan antara unit cost metode $\mathrm{ABC}$ dengan tarif INA- $\mathrm{CBG}^{\mathrm{ec}} \mathrm{S}$ yaitu sebesar Rp 1.442.814,00 dimana unit cost metode $\mathrm{ABC}$ lebih tinggi dibandingkan tarif INA CBG"s. Perlu adanya evaluasi terhadap proses pengkodingan kode diagnosis di rumah sakit agar klaim yang didapatkan sesuai dengan biaya yang dikeluarkan oleh rumah sakit dalam perawatan pasien, karena pada kasus ini penyakit penyerta pada pasien belum di masukkan dalam pengkodingan sehingga klaim yang di dapat lebih rendah dibandingkan jika penyakit penyerta tersebut di masukkan dalam proses pengkodingan

\section{SARAN}

Bagi RS Respira Yogyakarta :

a Manajemen perlu melakukan evaluasi dan efisiensi biaya terutama di biaya obat dan bahan habis pakai, dimana biaya tersebut memiliki jumlah yang besar, dengan cara membuat formularium obat dan barang habis pakai.

b. Penerpan clinical pathway dalam perawatan pasien, karena dengan penggunaan clinical pathway perawatan pasien lebih efektif dan biaya yang dikelurkan akan lebih terkontrol sesuai dengan tujuan dari clinical pathway yaitu kendali mutu dan kendali biaya.

c. Perlu adanya evaluasi terhadap proses pengkodingan kode diagnosis di rumah sakit agar klaim yang didapatkan sesuai dengan biaya yang dikeluarkan oleh rumah sakit dalam perawatan pasien, karena pada kasus ini penyakit penyerta pada pasien belum di masukkan dalam pengkodingan sehingga klaim yang di dapat lebih rendah dibandingkan jika penyakit penyerta tersebut di masukkan dalam proses pengkodingan.

Bagi peneliti selanjutnya:

Perlu dilakukannya penelitian untuk kasus rawat inap yang lainnya seperti penyakit jantung dan pembuluh darah yang perawatannya memerlukan waktu yang lama dan pembiaayaan yang tidak sedikit.

\section{DAFTAR PUSTAKA}

Aditama, Tjandra Yoga. 2004. MAnajemen administrasi rumah sakit. Jakarta : UI- Aditama, Tjandra Yoga. 2004. MAnajemen administrasi rumah sakit. Jakarta : UI-Press.

Agastya \& Arifa"ci, M. 2011. Unit Cost dan Tarif Rumah Sakit, Minat Utama Manajemen Rumah sakit: Yogyakarta.

Anggraini, D, 2008. Perbandingan kepuasan pasien gakin dan pasien umum di unit rawat inap RSUD budhi asih tahun 2008. Skripsi. Program sarjana fakultas kesehatan masyarakat Indonesia, depok.

Baker, J., J. 1998. Activity based costing and activity based management foe healthcare, aspen publisher, inc.

Budianto, W \& Sugiharto,M, 2013, „Biaya klaim INA CBGs dan biaya riil penyakit katastropik rawat inap peserta jamkesmas di rumah sakit studi di 10 rumah sakit milik kementrian kesehatan januari-maret 2012“e, Buletin Penelitian Sistem Kesehatan, 16(1) : 58-65.

Devitra, A, 2011, „Analisis implementasi clinical pathway kasus stroke berdasarkan INA-CBG's di rumah sakit stroke nasional bukittinggi tahun 2011"e, Jurnal penelitian. Program Pasca Sarjana Universitas Andalas, 
Gani, Ascobat, Analisis Kebijakan Tarif dalam Pelayanan Kesehatan, Seminar Optimalisasi Investasi Perorangan dan Kelompok di Bidang Pelayanan Kesehatan, Jakarta, 1993

Honsen \& Mowen, 2009, Managerial accounting (akutansi biaya), vol. 1, edk 8, Salemba Empat, Jakarta.

Matz \& Usry.1980. Cost Accounting: Planning and Control. Edisi 6, Chapter 22. USA: South Western Publishing Co.

Queensland Government, 2012, Patient Safety and Quality Improvement, Clinical Pathways www.qld.gov.au/psg/pathways.

Rahmanto A. 2009. Analisis Uji Beda Biaya Satuan Ibu Nyaris Meninggal Dengan Tarif DRG Depkes dan Pengembangan Perangkat Lunak Biaya Satuan di RSIA Budi Kemuliaan [tesis]. Depok : Pascasarjana Universitas Indonesia

Revans. 1986.Pemasaran Jasa dan Kualitas Pelayanan. Jakarta : Balai Buku Indonesia.

Sabarguna, Boy S. 2004. Sumber Daya Manusia Rumah sakit. Yogyakarta : Komsorsium RS Islam Jateng-DIY.

Undang-Undang Republik Indonesia Nomor 44 Tahun 2009, Rumah Sakit, Lembar Negara Republik Indonesia Nomor 5072, Jakarta.

World Health Organization (WHO) 2001, International Classificationof Functioning, Disabillity and Health. 